\title{
Anomalies of sea-ice transports in the Arctic
}

\author{
Torge MARTIN, ${ }^{1}$ Thomas MARTIN ${ }^{2}$ \\ ${ }^{1}$ Alfred Wegener Institute for Polar and Marine Research, PO Box 120161, D-27515 Bremerhaven, Germany \\ E-mail: torge.martin@awi.de \\ ${ }^{2}$ Leibniz Institute of Marine Sciences, IfM-GEOMAR, Düsternbrooker Weg 20, D-24105 Kiel, Germany
}

\begin{abstract}
In the Arctic, sea-ice motion and ice export are prominent processes and good indicators of Arctic climate system variability. Sea-ice drift is simulated using a dynamic-thermodynamic sea-ice model, validated with retrievals from SSM/I satellite observations. Both datasets agree well in reproducing the main Arctic drift patterns. In order to study inner Arctic transports and ice volume anomalies, the Arctic Ocean is split by ten boundaries, separating the central Arctic Ocean from the Nordic and marginal seas. It is found that the already dominant sea-ice export through Fram Strait has increased at the expense of export through the Barents Sea in the most recent years investigated. Furthermore, ice export from the Eurasian marginal seas increased slightly, followed by greater ice production during the winter. In contrast to this, the sea-ice volume moved within the Beaufort Gyre distinctly decreased. In total, the ice volume in the central Arctic decreased during the 40 year period covered by this study. The changes in the ice volume correspond to two wind-driven circulation regimes of the Arctic sea-ice motion, which recur approximately every 11 years. For the volume anomalies we derived a correlation of $\mathbf{- 0 . 5 9}$ to the North Atlantic Oscillation (NAO) index, lagging the NAO by 2 years.
\end{abstract}

\section{INTRODUCTION}

The Arctic sea-ice cover is a highly variable medium, which changes not only in extent (Walsh and Chapman, 2001) and thickness (Rothrock and others, 1999) on different timescales but also in its large-scale drift patterns (Rigor and others, 2002). Drift and thickness are correlated through the deformation process: convergent drift and shearing increases the thickness dynamically, and thick, deformed ice modifies the drift field through internal stress.

Since the 1990s it has become clear that the variability of the Arctic ice drift could not be only a small perturbation of the mean drift pattern. Observations provide a wide range of anomalies which are relatively persistent in time. The Beaufort Gyre (BG) and the Transpolar Drift Stream (TDS) are the well-known main features of Arctic sea-ice drift. The change in location and strength of these features is mostly modified by two wind-driven circulation regimes, which have been identified as the cause of most dominant variations of the Arctic sea-ice drift. Proshutinsky and Johnson (1997) estimated a cyclonic and an anticyclonic regime, alternating every 5-7years. Discussion of the concrete phases as well as the trigger and consequences (e.g. the effects on sea-ice transport) is still ongoing.

As a result of transport, sea ice does not melt where it forms. This leads to a net transport of fresh water and latent heat. Both melting and freezing play an important role in Arctic water mass stratification, and the drift itself influences the penetration of Atlantic Water into the Arctic. Melting of sea ice in the northern North Atlantic changes the conditions for formation of North Atlantic Deep Water as observed during great salinity anomalies and is thus an important part of global climate processes. For this reason, the ice export through Fram Strait (FS) has been investigated closely (Hilmer and others, 1998; Vinje and others, 1998; Kwok and Rothrock, 1999). However, the changes inside the Arctic basin have been studied less intensely.

The principal purpose of this study is to use a dynamicthermodynamic sea-ice model to investigate the variability of Arctic sea-ice drift and transport over interannual to decadal timescales. Firstly, a set of independent satellitederived ice-drift data (Martin and Augstein, 2000) was used to validate the simulated ice-drift pattern and time series of the model. The investigation of the regional ice area budget gives a first view of the variability of the ice flux on longer timescales. Finally, the model results have been used to strengthen the hypothesis of two recurring drift regimes and to investigate the consequences of these with respect to the Arctic sea-ice budget.

\section{DATA}

The satellite ice-drift data in this study are derived from 85.5 GHz brightness temperature images of the US Defense Meteorological Satellite Program (DMSP) Special Sensor Microwave/Imager (SSM/I) with an algorithm described in Martin and Augstein (2000). The daily average brightness temperature fields were provided by the US National Snow and Ice Data Center (NSIDC) (J. Maslanik and J. Stroeve, http://nsidc.org/data/nsidc-0001.html) on a regular grid with $12.5 \mathrm{~km}$ spatial resolution. The drift algorithm reduces the temporal resolution to a daily-generated 3 day average and a spatial running mean of about $300 \mathrm{~km}$ without affecting the data-point spacing of $37.5 \mathrm{~km}$. The $85.5 \mathrm{GHz}$ channel is sensitive to the liquid-water content of the atmosphere. Therefore, ice-drift derivations are limited to the winter season, between October and April.

Simulation results used in this study are obtained with a dynamic-thermodynamic sea-ice model with a viscousplastic rheology. Model dynamics are based on the formulation of Hibler (1979) with the thermodynamics of Parkinson and Washington (1979). The model parameters are set according to Harder (1996) as tested by Kreyscher and others (2000). The rotated model grid covers the whole Arctic and part of the North Atlantic with a nearly uniform horizontal resolution of $1^{\circ}(\sim 110 \mathrm{~km})$. The time-step is 24 hours. The model results cover 40 years from 1958 to 1997 , forced with the daily averaged atmospheric re-analysis data from the US National Centers for Environmental 

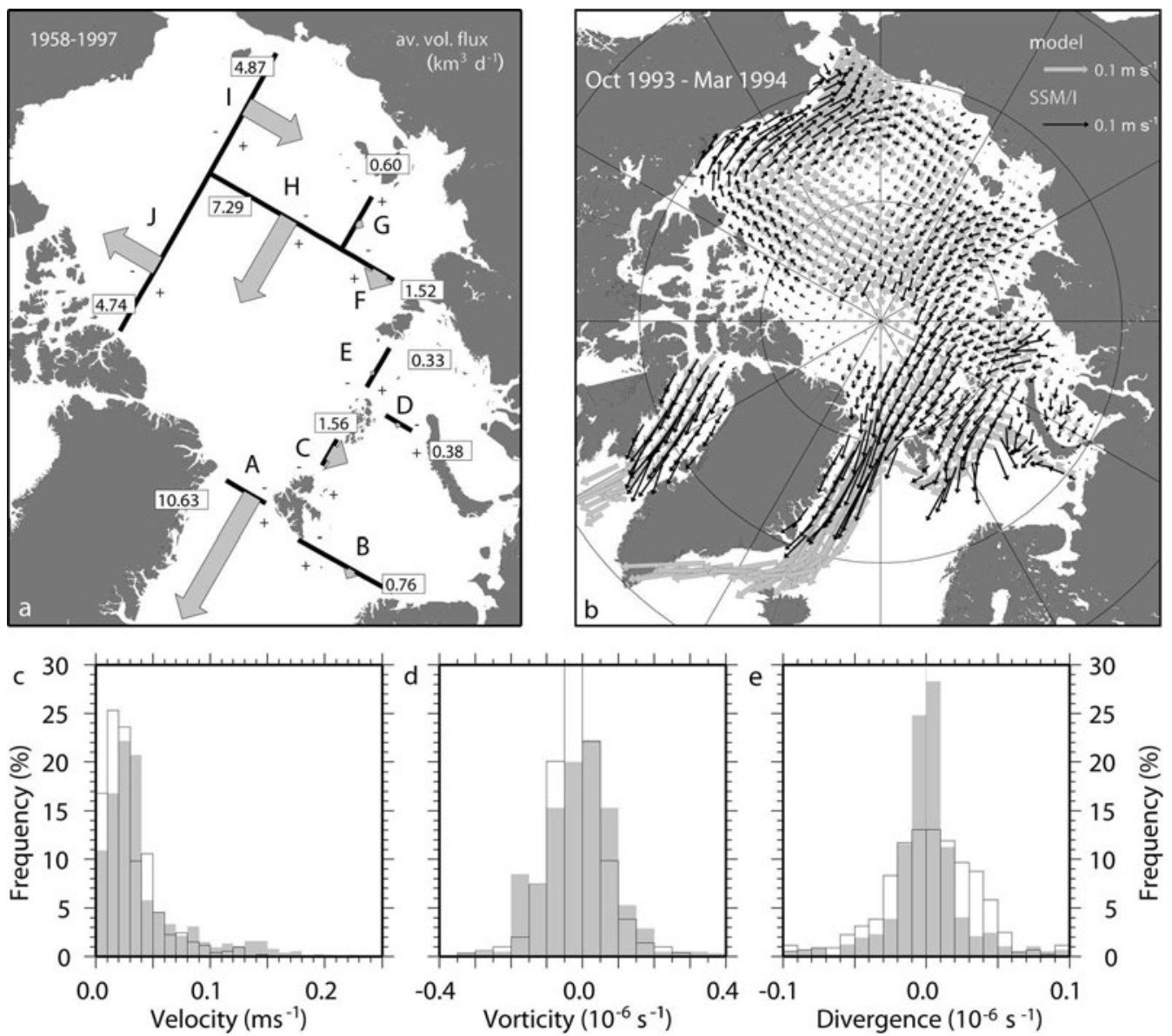

Fig. 1. (a) Mean sea-ice volume transports $\left(\mathrm{km}^{3} \mathrm{~d}^{-1}\right)$ from model results of the period 1958-97. Boundaries are labelled A-J, and the definition of signs for transport directions is given. (b) Sea-ice drift derived from SSM/I and model results representing an average of winter 1993/94 (October-March). (c) Frequency distribution of drift velocity of model (grey shade) and SSM/I data (black outline); (d) as (c) but showing the values of vorticity; (e) as (c) but showing the values of divergence in the drift fields.

Prediction and the US National Center for Atmospheric Research (NCEP/NCAR) and a climatological monthly mean for oceanic currents and heat exchange.

To compare the model results with the SSM/I data, it was necessary to adjust the temporal and spatial resolution of both datasets. The temporal resolution is limited by the 3 day mean of the SSM/I data, whereas the spatial resolution is determined by the $110 \mathrm{~km}$ spacing of the model grid. Model and SSM/I data overlap in five winters (1992-97) only.

The Arctic Ocean with its marginal seas has been separated by ten boundaries A-J in order to derive sea-ice transports (see Fig. 1a). The positioning of boundaries A-G is motivated by topography, whereas boundaries $\mathrm{H}-\mathrm{J}$ follow the mean position of the BG. The meeting point of lines $\mathrm{H}-\mathrm{J}$ is located at the centre of the BG as seen in the 40 year mean of the model data. This selection criterion is reasonable, as this study focuses on annual averaged sea-ice fluxes and the location of the centre of the BG shows very little variation on an interannual scale. The selected boundaries allow the calculation of sea-ice exports from the marginal seas to the Nordic seas as well as the flux within the BG.

\section{QUALITY OF SEA-ICE DRIFT}

Large-scale Arctic sea-ice drift varies on different timescales, from days to decades. The drift is determined predominantly by the surface wind field and internal forces but also driven by ocean currents and influenced by the topography and areas of fast ice during the winter months. Daily variability of the ice drift is dominated by temporally limited features such as tides, internal motion, ocean eddies and atmospheric cyclones. These result, especially during the summer, in erratic walks of single floes. This motion is only partly captured by drift estimates from model and satellite data because of the coarse spatial resolution and the necessity to parameterize subgrid processes in the model. However, this study focuses on the investigation of climate variability and interannual changes in ice transport. Our drift data are well suited for this purpose, by representing the drift of larger temporal and spatial scales.

The intercomparison of model and satellite data is restricted to winter means (October-March) of areal ice transport during the period 1992-97 because of the seasonal limitation of the $S S M / I$ data. To provide a first glimpse of the potential of both datasets, we present the winter of 1993/94 where the BG and the TDS, as the main features of Arctic sea-ice drift, are well pronounced in both datasets and hence show a pattern typical for two-thirds of the time covered by the model run. A direct comparison of model and SSM/I data is presented in Figure 1b. Larger discrepancies between model and SSM/I drift appear in the marginal ice zone, where the ice concentration is lower and thus ice generally follows free drift conditions. Along the ice edge, the algorithm used to derive the ice drift 

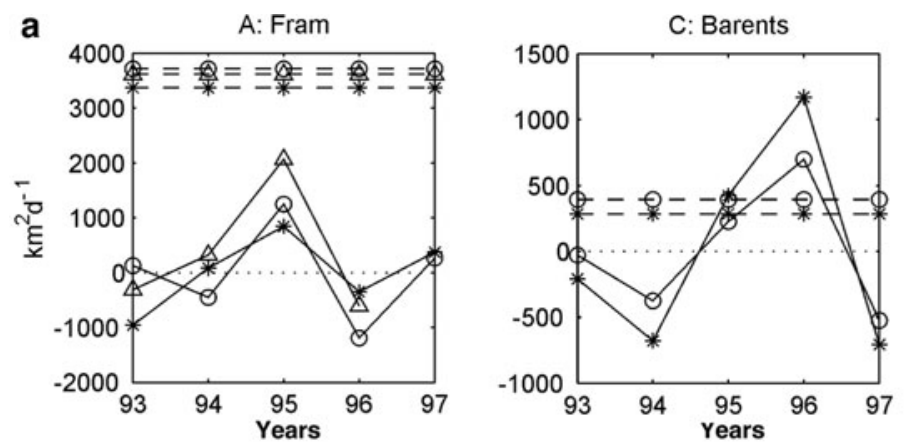

5 year means

(dashed):

- SSM/I (*)

- model (O)

- Vinje and others,1998 $(\Delta)$

Interannual anomalies

(solid):

- SSM/I (*)

- model (O)

- Vinje and others,1998 $(\Delta)$

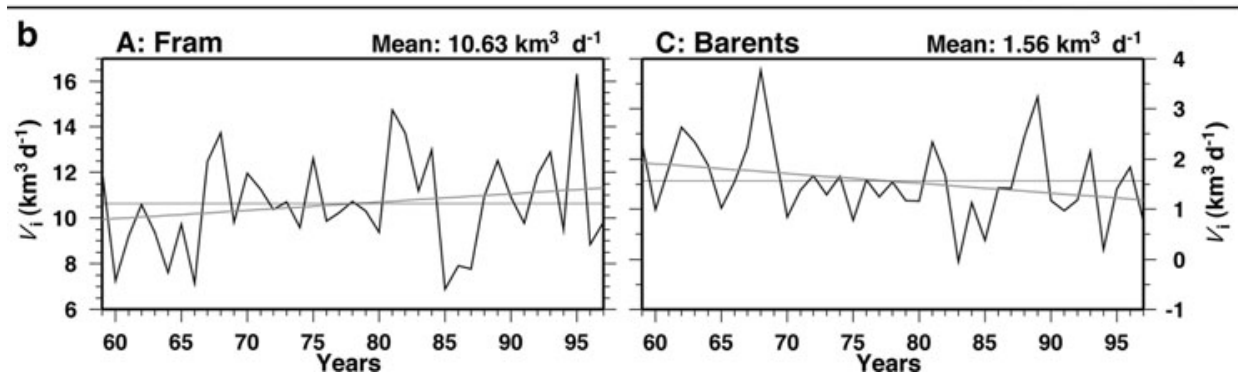

Fig. 2. (a) Five-year means and anomalies of ice areal fluxes from model and SSM/I data through FS and into Barents Sea. Signs of flux represent direction as shown in Figure 1a. (b) Modelled ice volume flux $\left(V_{\mathrm{i}}\right)$ : long-term means (dashed line), anomalies (solid black line) and trends (solid grey line) are shown.

from the SSM/I brightness temperature fields tends to detect the drift of single floes where no closed ice fields exist. A difference of importance to the following investigation occurs in the central Arctic, where orientation of the ice drift in both datasets differs. The model tends to a closed and stronger BG, whereas SSM/I data show the ice drifting towards FS, contributing to a wider TDS. These differences do not substantially hinder transport calculations, as they occur within a separated subregion rather than on a transport line, and drift velocities decrease towards Greenland and the Canadian Arctic Archipelago. Further deviations in drift, though small, occur in the Barents Sea, where they are mainly located along the coastlines. These uncertainties are most likely due to the coarse resolution of the forcing data (NCEP/NCAR wind at $10 \mathrm{~m}$ height) which do not allow for the representation of local effects in the model, or due to coastal processes which disrupt the algorithm used to derive the drift from SSM/I data. Again, larger deviations between the two datasets east of Novaya Zemlya do not affect the boundary regions directly.

An alternative view, which provides more confidence in the simulated ice-drift data, is given by the frequency distribution of the dynamic values as shown in Figure 1c-e. The distributions of velocity values for the model and satellite results agree well. The model simulates slightly larger drift velocities in the central Arctic, reflected by the difference of $0.01 \mathrm{~m} \mathrm{~s}^{-1}$ between the modal velocities. Comparing the modelled drift with observations from buoys did not reveal systematic errors; actually the model reproduces most buoy trajectories well. In contrast to this, the differences between satellite and model data in the histograms of vorticity and divergence (Fig. 1d and e) seem to be more prominent. Here, the satellite data feature more negative vorticity and a wider range of divergence values. This could be caused by the velocity profile between the centre of the BG and the coast. On the other hand, this distribution upholds our earlier assumption that the filter method has no effect on the quality of the satellite data archived. Additionally, Martin and Augstein (2000) showed that the SSM/I data resemble the buoy drift. However, the vorticity and divergence of the Arctic drift field cannot be derived from the raw data of buoy drift, as the spatial coverage is too sparse. Therefore, the derived values of difference for these variables give high confidence in the reliability of our model simulations.

\section{INNER ARCTIC SEA-ICE TRANSPORT}

Moving sea ice always implies transport of fresh water and latent heat, so that a thorough understanding of ice transport and its variability is of particular importance for process studies in the Arctic. The total ice volume flux is the product of drift velocity, concentration and thickness. During winter, when the ice concentration is high all over the Arctic, volume transport anomalies have two major causes which may act separately or together: velocity anomalies and thickness anomalies (Arfeuille and others, 2000). In this study, the significance of individual regions of the Arctic and the temporal variability are matters of particular interest. Therefore, the sea-ice transport was calculated for the entire Arctic, as well as for six different sub-areas, separated according to the local topography (Fig. 1a). This figure also includes the long-term ice volume budget.

Satellite data are restricted to the area ice flux. Figure $2 \mathrm{a}$ gives an example of the comparison between the satellite and the model data. The dominant ice areal export through FS agrees well with results from other studies (Vinje and others, 1998; Kwok and Rothrock, 1999), as can be seen in Figure 2a. A special case is boundaries F and G where anomalies of model and SSM/I data agree well but the means match only by taking the sum of both boundaries (not shown). This displays the different directions of export from the Laptev Sea preferred by the two datasets. Differences 

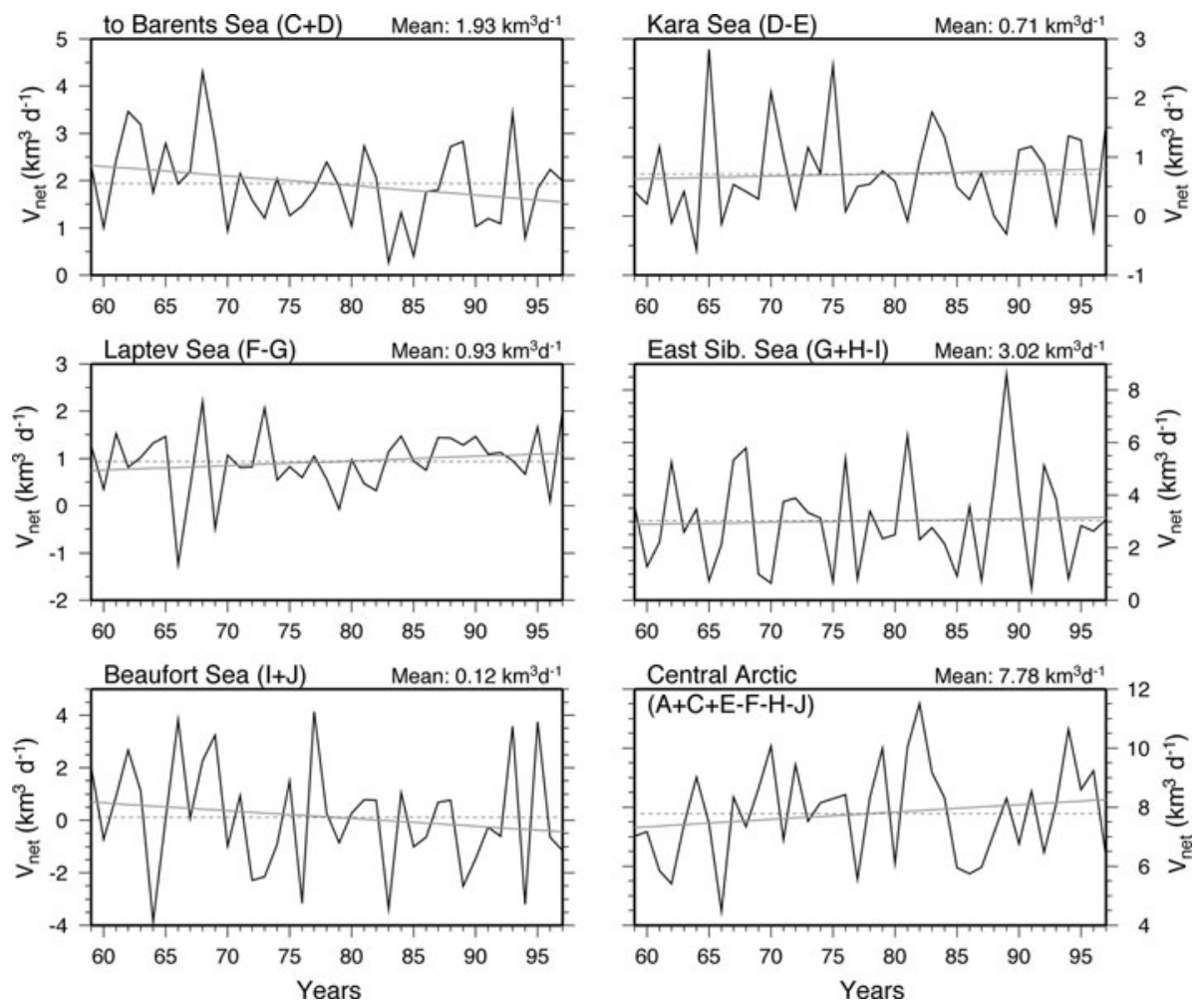

Fig. 3. Net volume ice export or, in case of Barents Sea, import ( $\left.V_{\text {net }}\right)$ of the six subregions. Boundaries separating these regions and the sign used for summing up the single transports are given in parentheses (cf. Fig. 1a). For line declaration see Figure $2 \mathrm{~b}$.

also occur in the marginal ice zone along boundary B due to the loose ice conditions resulting in discrepancies in drift velocity and deviations in ice extent between datasets. Apart from these discrepancies, model and satellite results agree well overall. Thus the modelled sea-ice volume flux is suitable for investigations of interannual and inter-decadal timescale, as Hilmer and Lemke (2000) and Kreyscher and others (2000) have proven the quality of ice thickness against observations and other models.

The annual mean volume flux is presented in Figure $2 b$ (boundaries $\mathrm{A}$ and $\mathrm{C}$ only). The formation of maxima in the FS ice volume export (e.g 1981-84), which are relevant for climatic events like great salinity anomalies, can be traced back over several years to ice volume anomalies in the Beaufort, Chukchi, East Siberian and/or Laptev Seas. In the 1981-84 case, the high export phase was fed by transport maxima out of the Laptev and East Siberian Seas during the period 1976-81 (not shown). An anomalously high volume of sea ice is transported within 3-4 years across the central Arctic basin towards FS. This is in good agreement with the findings of Rigor and others (2002).

The overall trends are also noteworthy (grey lines in Fig. 2b). The sea-ice volume flux through FS (A) increases conspicuously over the 40 year period. This might be a reason for the overall negative trend in the total Arctic seaice volume (Hilmer and Lemke, 2000). The increase in volume flux is only one effect of a general change in the seaice transport budget of the entire Arctic. In contrast to the FS transport, the export into the Barents Sea $(\mathrm{C})$ weakens during the investigation period. The drift seems to concentrate increasingly on FS (A) for ice export out of the Arctic Ocean. The latter is a direct response to the sea-level pressure gradient between the Greenland high and the Barents/Kara Sea low (Hilmer and others, 1998). Figure 3 summarizes the net ice volume export out of the six subregions. The total freshwater flux from the Arctic into the North Atlantic, which is the sum of the fluxes through FS (A) and the Barents Sea (B), increases during the investigation period. The annual reduction in the ice transport into the Barents Sea is about $0.02 \mathrm{~km}^{3} \mathrm{~d}^{-1}$, which does not totally balance the annual FS trend $\left(0.036 \mathrm{~km}^{3} \mathrm{~d}^{-1}\right)$.

Except for the Barents Sea, the Eurasian marginal seas are net producers of sea ice in the order East Siberian Sea, Laptev Sea, Kara Sea. The net export of these seas is slightly increasing $\left(0.007,0.010,0.004 \mathrm{~km}^{3} \mathrm{~d}^{-1}\right)$, leading to larger ice production during the winter. But this first-year ice is not thick enough to survive the following summer melt. This results in a retreat in extent of the Arctic ice cover during the last 30 years which is most obvious in summer but also detectable in winter (Walsh and Chapman, 2001). With respect to the mean ice production, the relative annual increase is largest in the Kara Sea. The decreasing variability of the volume export out of the Kara and Laptev Seas may be significant (Fig. 3). In the BG area the annual trend in ice transport is in the opposite direction to the mean flux, indicating that less ice is recycled in the $\mathrm{BG}$.

The annual ice transport budget in a given region is equal to the net ice production plus the advective changes in the total ice mass. Increasing ice export is associated with increasing ice production or with a reduction of the existing ice volume. The drift pattern indicates that all ice that reaches the Greenland or Barents Sea will eventually melt there. Similarly, it can be argued that all ice that leaves the Kara, Laptev or East Siberian Sea was formed in these shelf seas. The situation in the BG area is more difficult to interpret. While the ice volume in the central Arctic strongly decreases, this negative trend is much weaker in the 

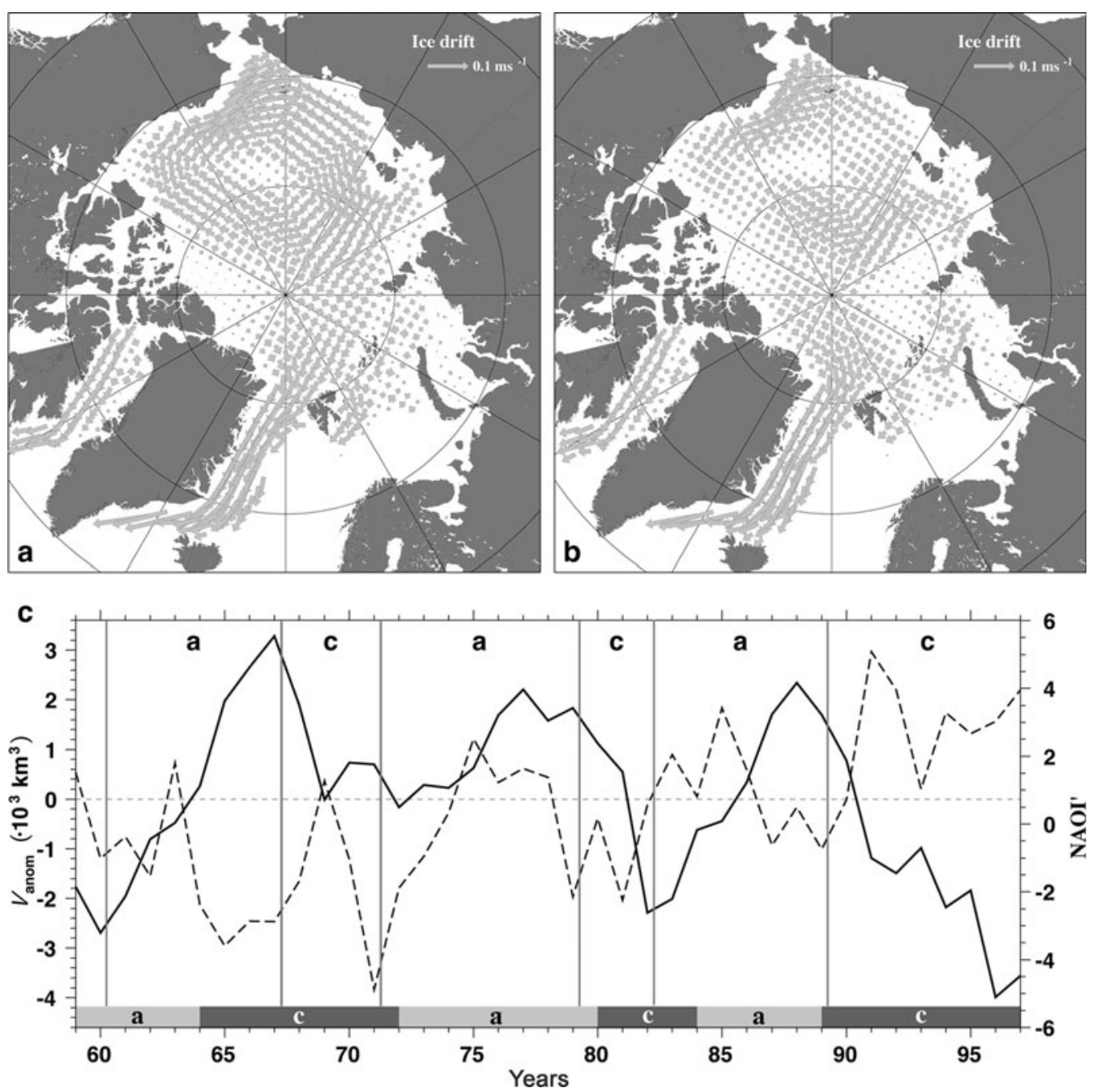

Fig. 4. (a) Composite of anticyclonic drift regime phases: 1960-67, 1971-79 and 1982-89. (b) Composite of cyclonic drift regime phases: 1967-71, 1979-82 and 1989-97. (c) Annual anomalies of the total Arctic sea-ice volume ( $V_{\text {anom, }}$ solid line) and NAO index, taken from Hurrell (1995; and J.W. Hurrell, http://www.cgd.ucar.edu/cas/jhurrell/indices.html), shifted 2 years to the right (NAOI', dashed line). The regime changes are marked with solid grey vertical lines and labelled above as cyclonic (c) and anticyclonic (a) phases; classification of Proshutinsky and Johnson (1997) is given as dark and light grey shaded bars at the bottom.

Beaufort Sea. There, the change in ice volume is dominated by recurring anomalies. This cycle was interrupted in the 1990s when ice volume stayed low. The import of ice into the Beaufort Sea from the American part of the BG (J) decreases with a trend of $0.047 \mathrm{~km}^{3} \mathrm{~d}^{-1}$, while the export in the Asian part (I) decreases at $0.076 \mathrm{~km}^{3} \mathrm{~d}^{-1}$. Hence an increasing amount of multi-year ice melts in this region during summer. This implies an increased freshwater input to this oceanic basin. Ice loss from the central Arctic by drifting may result in a decrease in the total Arctic ice volume or be compensated by the formation of new ice in this region. The latter involves an increased salt input to this central basin. These findings support the assumption that the central Arctic loses and the Beaufort Sea gains ice mass.

\section{DRIFT REGIMES}

Proshutinsky and Johnson (1997) proposed an alternation of two wind-driven circulation regimes in the motion of the Arctic sea-ice cover over a timescale of $5-7$ years. During the so-called anticyclonic phase, the drift is characterized by a dominant BG and a straight TDS. The second, cyclonic, regime features a weakened $\mathrm{BG}$ shifted towards the North
American coast, and a broadened, cyclonically curved TDS crossing the central Arctic basin.

In our model data, a similar ice-drift pattern is detectable by investigating annual means of ice-drift fields (Fig. 4a and b). The alternating drift regimes are found to be consistent with the variability of the total ice volume. The volume maxima of the entire Arctic sea-ice cover recur every 1011 years: 1967, 1978 and 1988 (see Fig. 4c). The ice volume anomalies amount to between $-4 \times 10^{3}$ and $+3 \times 10^{3} \mathrm{~km}^{3}$. Obviously the most intense volume reduction is closely related to a change of the circulation regime from the anticyclonic to the cyclonic drift pattern. In contrast to this, the largest ice volume occurs towards the end of the anticyclonic drift regime. During cyclonic drift phases, ice export towards the North Atlantic Ocean increases because the TDS is widened and more ice drifts towards FS. The widened TDS also transports thicker ice from north of Greenland and the Canadian Arctic Archipelago to FS. In addition, the ice-drift velocity tends to increase in the FS region in cyclonic years. All these factors lead, in varying degrees, to a decrease in total Arctic sea-ice volume. During anticyclonic phases, more ice is recycled within the BG, hence ice volume recovers. The entire phase of both regimes 
lasts approximately 11 years. The anticyclonic regime is present during 1960-67, 1971-79 and 1982-89, and the cyclonic regime during 1967-71, 1979-82 and 1989-97 (see Fig. 4). Only the last phase persists longer, covering the entire 1990s.

A clear consistency with the North Atlantic Oscillation (NAO) or Arctic Oscillation (AO) was not found when comparing the time series of these indices with the subdivision of the years into the drift regime phases. This is in contrast to Kwok (2000) and Rigor and others (2002), who retrieved this potential correspondence, assigning monthly means of sea-ice drift, disregarding their temporal order, to NAO and $\mathrm{AO}$ indices respectively. However, a reasonable correlation of $r=-0.59$ (exceeding the 95\% confidence interval) between ice volume anomalies and NAO index was found, taking a lag of 2 years into account (see Fig. 4c). This is in good agreement with Zhang and others (2004), who detected a link between the NAO and the total Arctic sea-ice volume, connected by the heat inflow over the Iceland-Scotland Ridge (ISR). They showed a reasonable correlation of $r=0.64$ between NAO index and ISR inflow and about $r=-0.6$ between ISR inflow and total Northern Hemisphere ice volume, where the latter is delayed by $2-3$ years and closely related to the Arctic seaice volume. The anomalies of their modelled ice volume match very well those shown in Figure 4c. A closer investigation of the phase of the lagged correlation shows that the connection is close in the 1960s $(r=-0.52)$ and again from the mid-1980s onwards $(r=-0.76)$ but not in between $(r=-0.18)$. Climate variability processes on longer timescales, which exceed the range of the 40 year time series used here, could also play an important role. Hence this link should be considered carefully and needs more intensive investigation.

The drift regime classification found here is partly displaced compared to that of Proshutinsky and Johnson (1997) (shown at the bottom of Fig. 4c). Composites of each of these two regimes are presented in Figure 4a (anticyclonic) and b (cyclonic). Notable differences between the two systems appear in drift velocities in the region north of $80^{\circ} \mathrm{N}, 60-120^{\circ} \mathrm{E}$, where the TDS is located during periods of anticyclonic drift, as well as in parts of the BG in the Beaufort and East Siberia Seas. Strong changes in drift direction appear around the North Pole and at the outlet of the Laptev Sea. Another difference is the fixed location of the centre of the BG in the means of both regimes (see Fig. 4a and b). While Proshutinsky and Johnson (1997) showed shifts in intensity as well as location of the gyre for both regimes, our dataset implies a strong gyre with a fixed centre during anticyclonic phases, and a retarded gyre with slight shifts of its centre during cyclonic phases. On average, these shifts in location during the cyclonic phase cancel each other out, so the centre location is the same as in the anticyclonic regime. Because of this stronger BG, the TDS is not able to expand as far towards the Beaufort Sea, as shown by Proshutinsky and Johnson (1997), although basically the same rotation occurs and, for example in the Laptev Sea, the change in drift direction is the same. It should be considered that the climatological oceanic forcing of the model strengthens the anticyclonic regime. This might also be the reason for the constancy of the BG centre in long-term averages. Changes in sea-ice drift pattern affect the inner Arctic transports discussed in the previous section and are consistent with changes in sea-ice volume.

\section{CONCLUSIONS}

The main objective of this study is a detailed investigation of sea-ice drift and transport within the Arctic. In preparation, modelled drift and areal transports have been compared to independent SSM/I-derived drift data. It is found that the two datasets agree well in their characterization of the two main drift patterns. Differences of $0.01 \mathrm{~m} \mathrm{~s}^{-1}$ on average in velocity and $<45^{\circ}$ in direction occur. However, differences along transport boundaries are most often even smaller. Areal transports agree well, especially concerning the detected anomalies. In general, ice exports from the marginal seas into the central Arctic basin are more reliable than the exchange between the marginal seas themselves. Larger differences in averaged transports occur where the boundaries are not given by topographical features. Vorticity and particularly divergence appear less uniform in the SSM/I data and might account for a variability of small-scale motion which cannot be resolved in this model. In summary, the results allow an investigation of drift and transport variability over longer scales using the entire 40 year model run. However, some of the conclusions are potentially limited since our model does not consider interannual variability of oceanic fields.

The anomalies of the ice production, which take place in the Laptev, East Siberian and Beaufort Sea regions, reach the central Arctic via the ice transport and can be identified in FS 3-4 years later. The average amount of ice volume exported towards the North Atlantic remains stable during the investigation period, though partly shifted from the Barents Sea to FS. At the same time, the exports from the Kara, Laptev and East Siberian Seas increase. The ice mass transported within the BG decreases and less multi-year ice reaches the central Arctic again. This means a shift of freshwater input towards the Beaufort Sea and an increased salt input in the central basin as the multi-year sea-ice cover becomes less compact and more open water may refreeze. However, the trends in sea-ice transport shown in this study refer to the investigated 40 year period.

Finally, it is shown that the two wind-driven circulation regimes of the Arctic sea-ice cover are closely related to the anomalies of the total sea-ice volume. More ice is exported through FS during cyclonic years when the TDS is dominant. During anticyclonic phases the ice volume recovers. Timescales over which these interrelations can be analyzed can still only be attained by modelling.

\section{ACKNOWLEDGEMENTS}

The daily SSM/I brightness temperature data were obtained from the EOSDIS NSIDC Distributed Active Archive Center (NSIDC DAAC). NAO index data were provided by the Climate Analysis Section, NCAR, Boulder, USA. The atmospheric forcing data were derived from NCEP/NCAR reanalysis. We thank M. Hilmer for contributing his model results.

\section{REFERENCES}

Arfeuille, G., L.A. Mysak and L.-B. Tremblay. 2000. Simulation of the interannual variability of the wind-driven Arctic sea-ice cover during 1958-1998. Climate Dyn., 16(2-3), 107-121.

Harder, M. 1996. Dynamik, Rauhigkeit und Alter des Meereis in der Arktis - numerische Untersuchungen mit einem grossskaligen Modell. Ber. Polarforsch. 203. 
Hibler, W.D., III. 1979. A dynamic thermodynamic sea ice model. J. Phys. Oceanogr., 9(4), 815-846.

Hilmer, M. and P. Lemke. 2000. On the decrease of Arctic sea ice volume. Geophys. Res. Lett., 27(22), 3751-3754.

Hilmer, M., M. Harder and P. Lemke. 1998. Sea ice transport: a highly variable link between Arctic and North Atlantic. Geophys. Res. Lett., 25(17), 3359-3362.

Hurrell, J.W. 1995. Decadal trends in the North Atlantic Oscillation: regional temperature and precipitation. Science, 269(5224), 676-679.

Kreyscher, M., M. Harder, P. Lemke and G.M. Flato. 2000. Results of the Sea Ice Model Intercomparison Project: evaluation of sea ice rheology schemes for use in climate simulations. J. Geophys. Res., 105(C5), 11,299-11,320.

Kwok, R. 2000. Recent changes in Arctic Ocean sea ice motion associated with the North Atlantic Oscillation. Geophys. Res. Lett., 27(6), 775-778.

Kwok, R. and D.A. Rothrock. 1999. Variability of Fram Strait ice flux and North Atlantic Oscillation. J. Geophys. Res., 104(C3), $5177-5189$
Martin, T. and E. Augstein. 2000. Large-scale drift of Arctic sea ice retrieved from passive microwave satellite data. J. Geophys. Res., 105(C4), 8775-8788.

Parkinson, C.L. and W.M. Washington. 1979. A large-scale numerical model of sea ice. J. Geophys. Res., 84(C1), 311-337.

Proshutinsky, A.Y. and M.A. Johnson. 1997. Two circulation regimes of the wind-driven Arctic Ocean. J. Geophys. Res., 102(C6), 12,493-12,514.

Rigor, I.G., J.M. Wallace and R.L. Colony. 2002. Response of sea ice to the Arctic Oscillation. J. Climate, 15(18), 2648-2663.

Rothrock, D.A., Y. Yu and G.A. Maykut. 1999. Thinning of the Arctic sea-ice cover. Geophys. Res. Lett., 26(23), 3469-3472.

Vinje, T., N. Nordlund and Å.S. Kvambekk. 1998. Monitoring ice thickness in Fram Strait. J. Geophys. Res., 103(C5), 10,437-10,450.

Walsh, J.E. and W.L. Chapman. 2001. 20th-century sea-ice variations from observational data. Ann. Glaciol., 33, 444-448.

Zhang, J., M. Steele, D.A. Rothrock and R.W. Lindsay. 2004. Increasing exchanges at Greenland-Scotland Ridge and their links with the North Atlantic Oscillation and Arctic sea ice. Geophys. Res. Lett., 31(9), L09307. (10.1029/2003GL019304.) 